BMC

Plant Biology

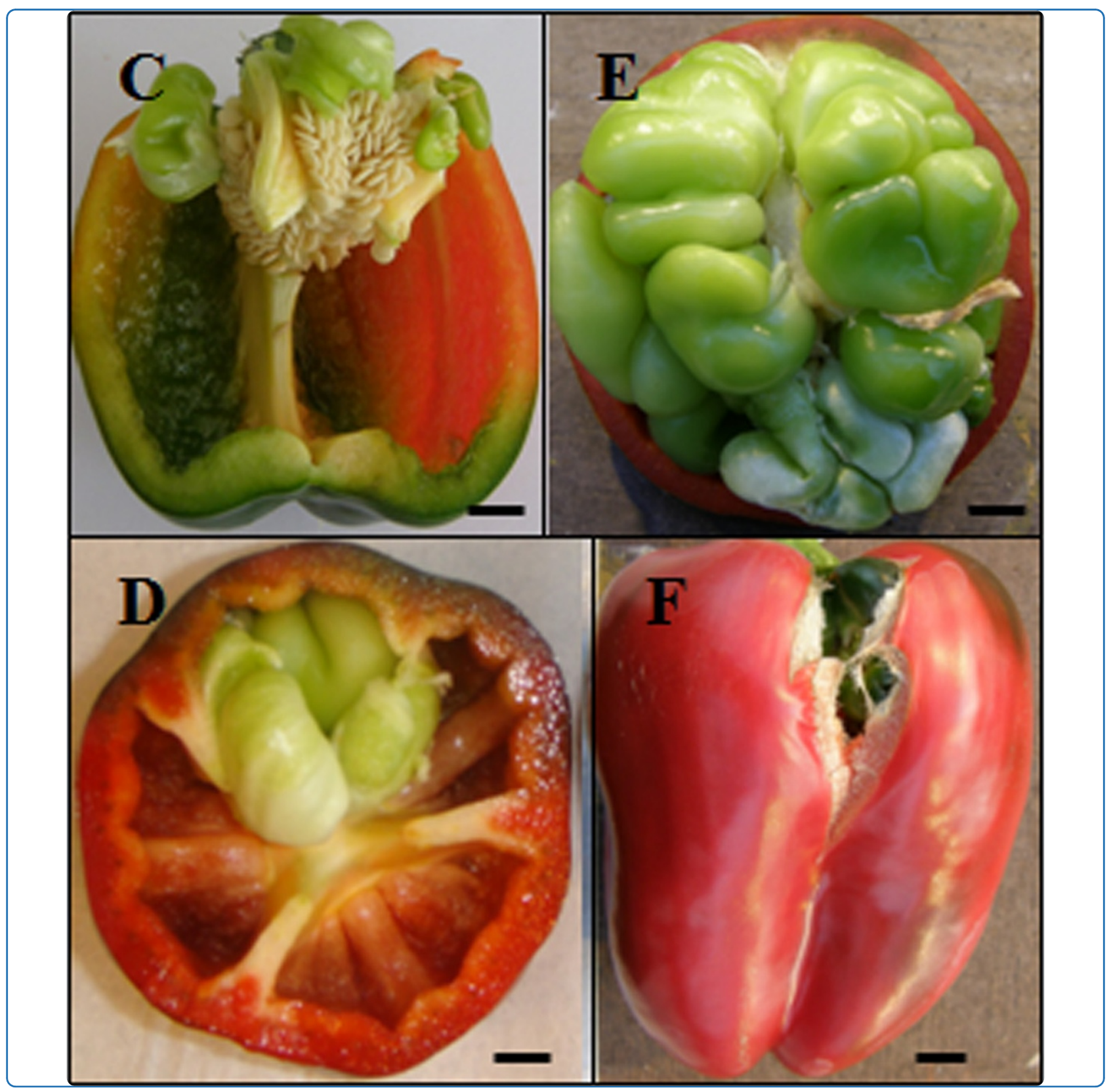

Parthenocarpic potential in Capsicum annuum L. is enhanced by carpelloid structures and controlled by a single recessive gene

Tiwari et al. 


\title{
Parthenocarpic potential in Capsicum annuum L. is enhanced by carpelloid structures and controlled by a single recessive gene
}

\author{
Aparna Tiwari ${ }^{1}$, Adam Vivian-Smith ${ }^{2,5}$, Roeland E Voorrips ${ }^{3}$, Myckel EJ Habets ${ }^{2}$, Lin B Xue ${ }^{4}$, Remko Offringa ${ }^{2}$ and \\ Ep Heuvelink ${ }^{1 *}$
}

\begin{abstract}
Background: Parthenocarpy is a desirable trait in Capsicum annuum production because it improves fruit quality and results in a more regular fruit set. Previously, we identified several $C$. annuum genotypes that already show a certain level of parthenocarpy, and the seedless fruits obtained from these genotypes often contain carpel-like structures. In the Arabidopsis bel1 mutant ovule integuments are transformed into carpels, and we therefore carefully studied ovule development in C. annuum and correlated aberrant ovule development and carpelloid transformation with parthenocarpic fruit set.
\end{abstract}

Results: We identified several additional C. annuum genotypes with a certain level of parthenocarpy, and confirmed a positive correlation between parthenocarpic potential and the development of carpelloid structures. Investigations into the source of these carpel-like structures showed that while the majority of the ovules in $C$. annuum gynoecia are unitegmic and anatropous, several abnormal ovules were observed, abundant at the top and base of the placenta, with altered integument growth. Abnormal ovule primordia arose from the placenta and most likely transformed into carpelloid structures in analogy to the Arabidopsis bel1 mutant. When pollination was present fruit weight was positively correlated with seed number, but in the absence of seeds, fruit weight proportionally increased with the carpelloid mass and number. Capsicum genotypes with high parthenocarpic potential always showed stronger carpelloid development. The parthenocarpic potential appeared to be controlled by a single recessive gene, but no variation in coding sequence was observed in a candidate gene CaARF8.

Conclusions: Our results suggest that in the absence of fertilization most $C$. annuum genotypes, have parthenocarpic potential and carpelloid growth, which can substitute developing seeds in promoting fruit development.

\section{Background}

Pollination and fertilization are required in most flowering plants to initiate the transition from a fully receptive flower to undergo fruit development. After fertilization the ovules develop into seeds and the surrounding carpels develop into the fruit, while in the absence of fertilization the ovules degenerate and growth of the surrounding carpels remains repressed [1]. The initiation of fruit set can be uncoupled from fertilization, and this results in the development of seedless or

\footnotetext{
* Correspondence: ep.heuvelink@wur.nl

'Horticultural Supply Chains, Plant Sciences Group, Wageningen University, P.

O. Box 630, 6700 AP Wageningen, The Netherlands

Full list of author information is available at the end of the article
}

parthenocarpic fruits. This can be achieved by ectopic application or artificial overproduction of plant hormones [1], or by mutating or altering the expression of specific genes. In Arabidopsis, the fruit without fertilization (fwf) mutant that develops parthenocarpic fruit [2] has a lesion in the AUXIN RESPONSIVE FACTOR 8 (ARF8) gene [3]. Expression of an aberrant form of Arabidopsis ARF8 also conferred parthenocarpy in Arabidopsis and tomato, indicating ARF8 as an important regulator in the control of fruit set [4]. Mapping of a parthenocarpic QTL in tomato further suggests a role for ARF8 in fruit set [5].

Fruit set is normally initiated by two fertilization events occurring in the ovules. Ovules are complex

\section{Biomed Central}


structures found in all seed bearing plants, comprising protective integuments that surround the megagametophyte leaving an opening referred to as the micropyle. When the pollen tube successfully enters the micropyle of the mature ovule, it releases two sperm cells that combine with respectively the egg cell and the central cell. These sites of cell fusion are considered as primary locations from where signalling triggers fruit set $[1,6]$. After fertilization, the integuments grow and expand to accommodate the developing endosperm and embryo, but they also apparently have a role in coordinating the growth of both fruit and seeds [1]. Various Arabidopsis mutants have been identified where ovules show disrupted integument growth, such as aintegumenta (ant; lacks inner and outer integuments), aberrant testa shape (ats; contains a single integument), inner no outer integument (ino; the absence of outer integument growth on the ovule primordium), short integuments1 ( $\sin 1$; where both integuments are short), and bell and apetala2 (ap2) [7-12]. In the latter two loss-of-function mutants ovule integuments are converted into carpelloid structures [11-13]. Interestingly, two specific mutants have been reported to affect parthenocarpic fruit development of the Arabidopsis fwf mutant. Firstly, the ats-1/ kan4-1 loss-of-function mutation enhances the $f w f$ parthenocarpic phenotype, suggesting that modification of the ovule integument structure influences parthenocarpic fruit growth [2]. Secondly, parthenocarpic fruit development was also enhanced in the bel1-1 fwf-1 double mutant, and at the same time a higher frequency of carpelloid structures was observed compared to the bel1-1 single mutant [14]. This suggests on the one hand that carpelloid structures enhance parthenocarpic fruit development, and on the other hand that the development of carpelloid structures is enhanced in the absence of seed set [14].

Parthenocarpy is a desired trait in Capsicum annuum (also known as sweet pepper), as it is expected to minimize yield fluctuations and enhance the total fruit production while providing the inclusion of a quality trait [15]. Research into the developmental and genetic basis for parthenocarpy in C. annuum is limited. Several C. annuиm genotypes have been identified that show tendencies for facultative parthenocarpic fruit development [16]. Seedless fruit from these facultative genotypes display a high frequency of carpelloid structures at low night temperatures [16]. To understand the relationship between parthenocarpic potential and the presence of carpelloid structures, we investigated ovule development and the occurrence of abnormal ovules in C. annuum genotypes possessing a range of high (Chinese Line 3), moderate (Bruinsma Wonder) and low (Orlando) potential for parthenocarpic fruit set. Our results show that parthenocarpy in C. annuum can promote carpelloid ovule proliferation and that an appropriate genetic background enhances the transformation of ovules which can in turn further stimulate seedless fruit growth. Five selected genotypes that differed most in their parthenocarpic fruit development and carpelloid ovule growth were evaluated to identify a possible correlation between these two traits. Through genetic analysis with crosses between Line 3 and contrasting parents we linked the parthenocarpic potential of this genotype to a single recessive gene. Furthermore sequence analysis showed that the parthenocarpic potential already present in $C$. annuum genotypes is not caused by a mutation in CaARF8.

\section{Results}

Parthenocarpy is widely present in Capsicum annuum L. genotypes

To test whether parthenocarpy is widely present in $C$. annuum, twelve genotypes were evaluated for their parthenocarpic potential by emasculating flowers (Table 1). Included in this comparison was Bruinsma Wonder (BW), which has been shown to have moderate levels of parthenocarpy [16]. All genotypes except Parco set seedless fruit after emasculation, indicating a wide occurrence of parthenocarpy in C. annuum genotypes (Table 1). Additionally, carpelloid structures were also reported present in most parthenocarpic fruit from the $C$. annuиm genotypes previously studied [16], and here we investigate the origin and effect of these structures on fruit initiation.

\section{Number and weight of carpelloid structures is influenced by genotype}

To study whether a positive relation between carpelloid development and parthenocarpy occurs in most of the genotypes of $C$. аnnuum, we tested five different genotypes, each showing a different potential for parthenocarpic fruit set, at two different temperatures: $20 / 18^{\circ} \mathrm{C}$ $\mathrm{D} / \mathrm{N}$ as a normal temperature and $16 / 14^{\circ} \mathrm{C} \mathrm{D} / \mathrm{N}$ as a low temperature. Previous analysis showed that parthenocarpy is enhanced when plants are grown at low temperature [16]. Pollen viability and pollen germination were significantly reduced at low temperature $(\mathrm{P}<$ 0.001) compared to normal temperature (Additional file 1 ), suggesting that the reduced fertility might enhance the occurrence of observed parthenocarpy. For the nonpollinated category of flowers, pollination was prevented by applying lanolin paste on the stigma of non-emasculated flowers around anthesis. However at normal temperature some flowers were already pollinated before the lanolin application, resulting in seeded fruit (between 1-60 seeds/fruit). At maturity, both seeded and seedless fruits were harvested and the seedless fruits were further characterized into parthenocarpic fruits 
Table 1 Parthenocarpic potential in thirteen genotypes of Capsicum annuum

\begin{tabular}{llcc}
\hline Genotype & Accession number & Number of emasculated flowers & Fruit set (\%) \\
\hline Neusiedler Ideal; Stamm S & CGN21562 & 66 & 41 \\
Keystone Resistant Giant & CGN23222 & 82 & 39 \\
Yellow Belle & CGN22851 & 78 & 38 \\
Sweet boy & CGN23823 & 58 & 38 \\
Green King & CGN22122 & 69 & 36 \\
Wino Treib OEZ & CGN23270 & 110 & 35 \\
Bruinsma Wonder & CGN19226 & 88 & 35 \\
Riesen v.Kalifornien & CGN22163 & 79 & 34 \\
Florida Resistant Giant & CGN16841 & 75 & 32 \\
Emerald Giant & CGN21493 & 73 & 32 \\
Spartan Emerald & CGN16846 & 137 & 16 \\
California Wonder 300 & CGN19189 & 141 & 13 \\
Orlando* & De Ruiter Seeds & - & 0 \\
Parco & CGN23821 & 149 & 0 \\
Lamuyo B* & De Ruiter Seeds & - & \\
\hline
\end{tabular}

The accession numbers are from the Center of Genetic Resources, the Netherlands (CGN), The number of emasculated flowers and the percentage of flowers that set into fruit is indicated

*referred from (16)

and knots. Only those seedless fruits that reached at least $50 \%$ of the weight of seeded fruits (i.e. only fruits of at least $76 \mathrm{~g}$ ) were considered as true parthenocarpic fruit, while remaining seedless fruits were considered as "knots", which are characterized as small seedless fruits discarded by industry due to their failure to achieve significant size and colour $[16,5]$. Taking this criterion into account at normal temperatures Line 3 resulted in 89\% seedless fruits (89\% parthenocarpic fruits and 0\% knots) and $11 \%$ seeded fruits while Parco resulted in $78 \%$ seedless fruits (56\% parthenocarpic fruits and $22 \%$ knots) and $22 \%$ seeded fruits.

At normal temperatures parthenocarpic fruit set and carpelloid growth were clearly genotype dependent (Figure 1), and we observed a strong positive correlation between carpelloid weight and number together with the percentage of parthenocarpic fruit produced. The carpelloid weight was significantly higher in non-pollinated flowers (Figure 1A, B). After preventing pollination, Line 3 showed the highest parthenocarpy (89\% of fruits were seedless, excluding knots), and produced the highest number $(10 \pm 1.16)$ and weight $(17 \pm 2.6 \mathrm{~g})$ of carpelloid structures per fruit. In contrast, Parco showed lowest parthenocarpy (56\%) with the lowest number and weight of carpelloid structures per fruit $(1.6 \pm 0.37$ and $2.8 \pm 0.7$ g, respectively; Figure 1A-B). Even after hand pollination, a positive relationship between the number and mass of carpelloid structures and the level of seedlessness was observed (Figure 1C-D).

Evaluation of the same five genotypes at the low temperature regime showed increased parthenocarpy but decreased carpelloid growth though the correlation between parthenocarpy and carpelloid structures remained present (Figure 1E-H). Furthermore, at low temperatures $\left(16 / 14^{\circ} \mathrm{C} \mathrm{D} / \mathrm{N}\right)$ lanolin application promoted the production of seedless fruits in each cultivar. This resulted for Line 3 in $88 \%$ parthenocarpic fruits and $12 \%$ knots while Parco had $71 \%$ parthenocarpic fruits and 29\% knots. Again Line 3 showed the highest parthenocarpy with the highest number $(4 \pm 1.1)$ and weight $(11 \pm 2.2 \mathrm{~g})$ of carpelloid structures, in contrast to Parco where the lowest level of parthenocarpy was observed concomitantly together with a low number (1 $\pm 0.44)$ and weight $(2 \pm 1.15 \mathrm{~g})$ of carpelloid structures (Figure 1E-F). A positive correlation between the presence of naturally occurring parthenocarpic fruit and carpelloid structures was also observed in pollinated flowers (Figure 1G-H). In conclusion, under different temperature conditions and after different treatments (i. e. pollination and where pollination was prevented), a positive correlation was observed between percentages of parthenocarpic fruits and the final number and weight of carpelloid structures.

\section{The occurrence of abnormal ovule development in $C$. annuum}

To study the basis of both parthenocarpic potential and carpelloid proliferation we used scanning electron microscopy to assess deviations in ovule development in specific Capsicum genotypes. C. annuum has an axillar placenta, where ovules develop in a gradient from top to bottom as shown in genotype Orlando (OR), BW, and Line 3 (Figure 2A-C). Normally the ovule primordium initiates as a protrusion from the placental tissue, and this differentiates into three main proximal-distal elements, respectively known as the funiculus, the chalaza 

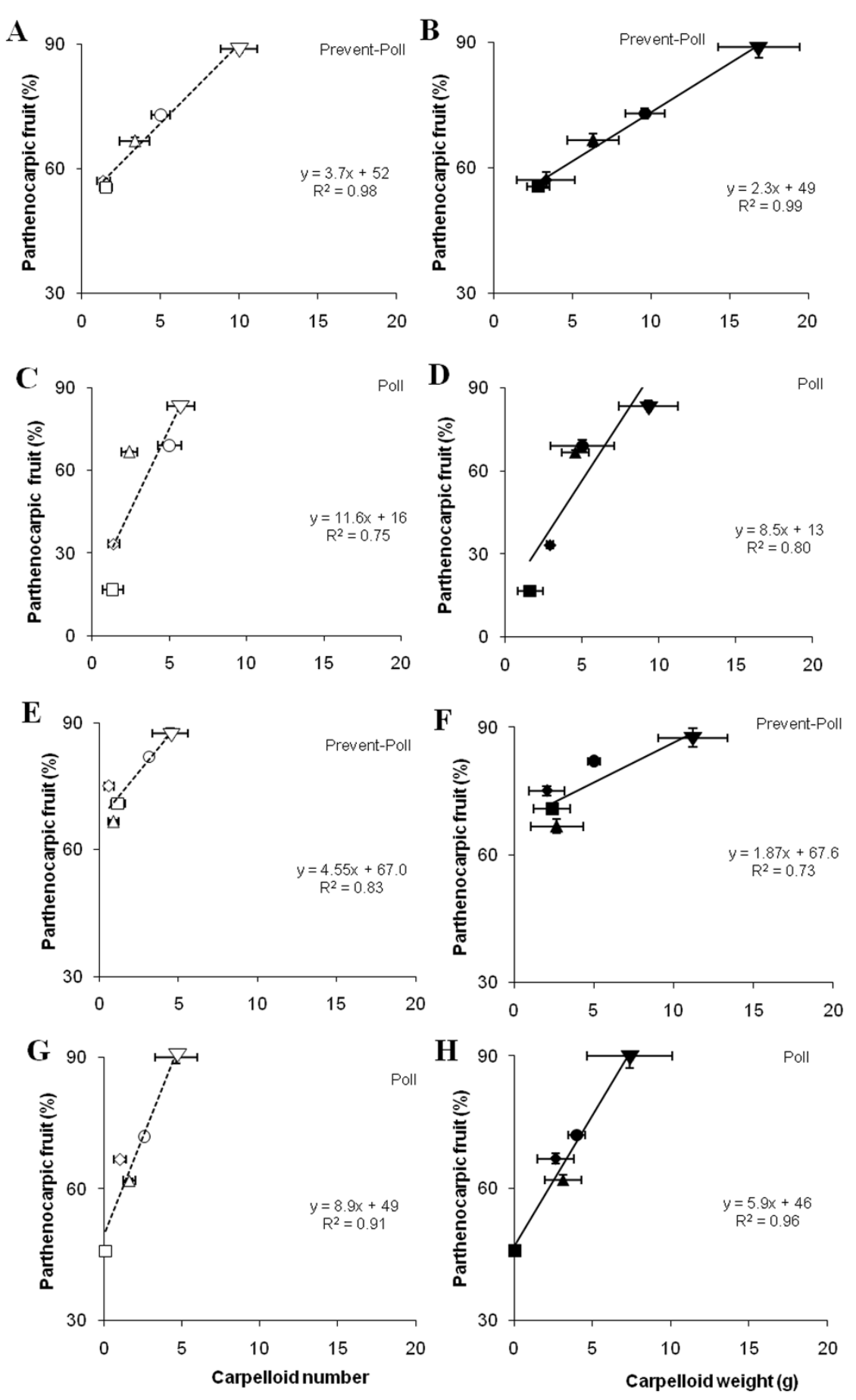

Figure 1 Genotype-specific evaluation of the percentage of seedless fruits and carpelloids structure (CLS) development. A-H: Correlation between the percentage of parthenocarpic fruits (only those fruits were counted that reached at least $50 \%$ of the weight of seeded fruits) and the mean CLS number (unfilled symbol) and weight (g) (filled symbol) per fruit in the genotypes Parco $(\boldsymbol{n}=18-24)(\boldsymbol{\bullet}, \square)$, California Wonder $(\boldsymbol{n}=18-24)(\bullet, 0)$, Riesen v. Californien $(\boldsymbol{n}=18-24)(\boldsymbol{\Delta}, \Delta)$, Bruinsma Wonder $(\boldsymbol{n}=92-146)(\bullet, 0)$, and Line $3(\boldsymbol{n}=18-24)(\mathbf{v}, \nabla)$, at normal 20/ $18^{\circ} \mathrm{C}$ D/N (A-D) and low $16 / 14^{\circ} \mathrm{C}$ D/N (E-H) temperatures following hand pollination (Poll; $\left.C, D, G, H\right)$, or prevention of pollination by applying lanolin paste on the stigma at anthesis (Prevent-Poll; $A, B, E, F)$. The regression lines are based on the means of the five Capsicum annuum genotypes. 




Figure 2 Cryo-scanning electron microscopy images of ovule development in Capsicum annuum. A-C, Comparison of genotypes Orlando (A), Bruinsma Wonder (B), and Line $3(C)$ grown at $20 / 18^{\circ} \mathrm{C}$ D/N. Gradient of ovule development from top to bottom (arrow head; small circle: undeveloped ovules) Bar $=1 \mathrm{~mm}$. D,E, Ovule primordia (op) initiated from the placenta (arrows), and differentiated in nucellus (nu), chalaza (ch) and funiculus (fu), integument development (E) and development of the micropyle (F). F, Single integument (unitegmic) ovules with micropylar end (mi) situated near the base of the funiculus and oriented towards the placenta (anatropous). Bar $=100 \mu \mathrm{m}$.

and the distally-located nucellus. The funiculus is comprised of a stalk-like structure and often contains vascular tissues that connect the ovule to the placenta. The chalaza in Capsicum is characterized by the presence of a single integument, indicating that the ovule is unitegmic in nature. This integument gradually grows to cover the nucellus leaving a micropylar opening. Typical for an anatropous ovule, at anthesis the micropylar end is oriented towards the placenta (Figure 2D-F).

Capsicum genotypes OR, BW, and Line 3 each contained abnormal ovules, which were most abundant at the top and base of the placenta. Ovule abnormalities were most often detected after the integument growth had been initiated and various types of integument abnormalities were observed. For example integument development expanded abnormally across the ovule primordia or proximo-distally to form carpelloid structures (Figure 3A, B). In some cases the funiculus failed to cease growth at the normal length and the nucellus expanded, forming excessively long ovules in which the integument failed to cover the nucellus (Figure 3B). In other cases the integument failed to cover the nucellus, as the integument-like structure did not proliferate from the distal but rather from the more proximal end (Figure 3C). Ovule primordia were also observed to be transformed into amorphic or staminoid tissues (Figure 3D). Others lost the normal anatropous development and took on a "hairdryer" phenotype, reminiscent of the superman phenotype [17] (Figure 3E) or only differentiated into a funiculus lacking distal elements (Figure 3F).

\section{Abnormal ovule development correlates with reduced seed set and enhanced development of carpelloid structures}

To test the effect of aberrant ovule development on seed set and carpelloid growth, we quantified the number of aberrant ovules in genotypes Line 3 and OR by evaluating six gynoecia per genotype and 20-30 ovules per gynoecium, and we quantified the seed number by evaluating fruits in Line $3(n=5)$ and OR $(n=55)$. The percentage of aberrant ovules was significantly higher in Line 3 compared to OR ( $14 \%$ versus $6 \%, P=0.001$ ), while the number of seeds was lower in Line 3 compared to OR (21 versus 79, $P=0.040$ ) (Figure 4A). Carpelloid growth was already observed within a week after anthesis in Line 3, and after 2 weeks in OR, suggesting early development in Line 3.

To evaluate a possible role of reduced female fertility as a cause of reduced seed set in Line 3 , we quantified the number of seeds in Line 3 and BW at low, normal and high night temperature. Pollination was done by vibrating the main shoot two times per week. Previously, $20^{\circ} \mathrm{C}$ was reported as an optimum temperature for flowering and fruit set in C. annuиm, and a temperature below $16^{\circ} \mathrm{C}$ was reported to increase the percentage of seedless fruit $[18,19]$. Therefore we contrasted $20 / 18^{\circ} \mathrm{C}$ $\mathrm{D} / \mathrm{N}$ with $16 / 14^{\circ} \mathrm{C} \mathrm{D} / \mathrm{N}$ as a low temperature and $24 / 22^{\circ}$ 


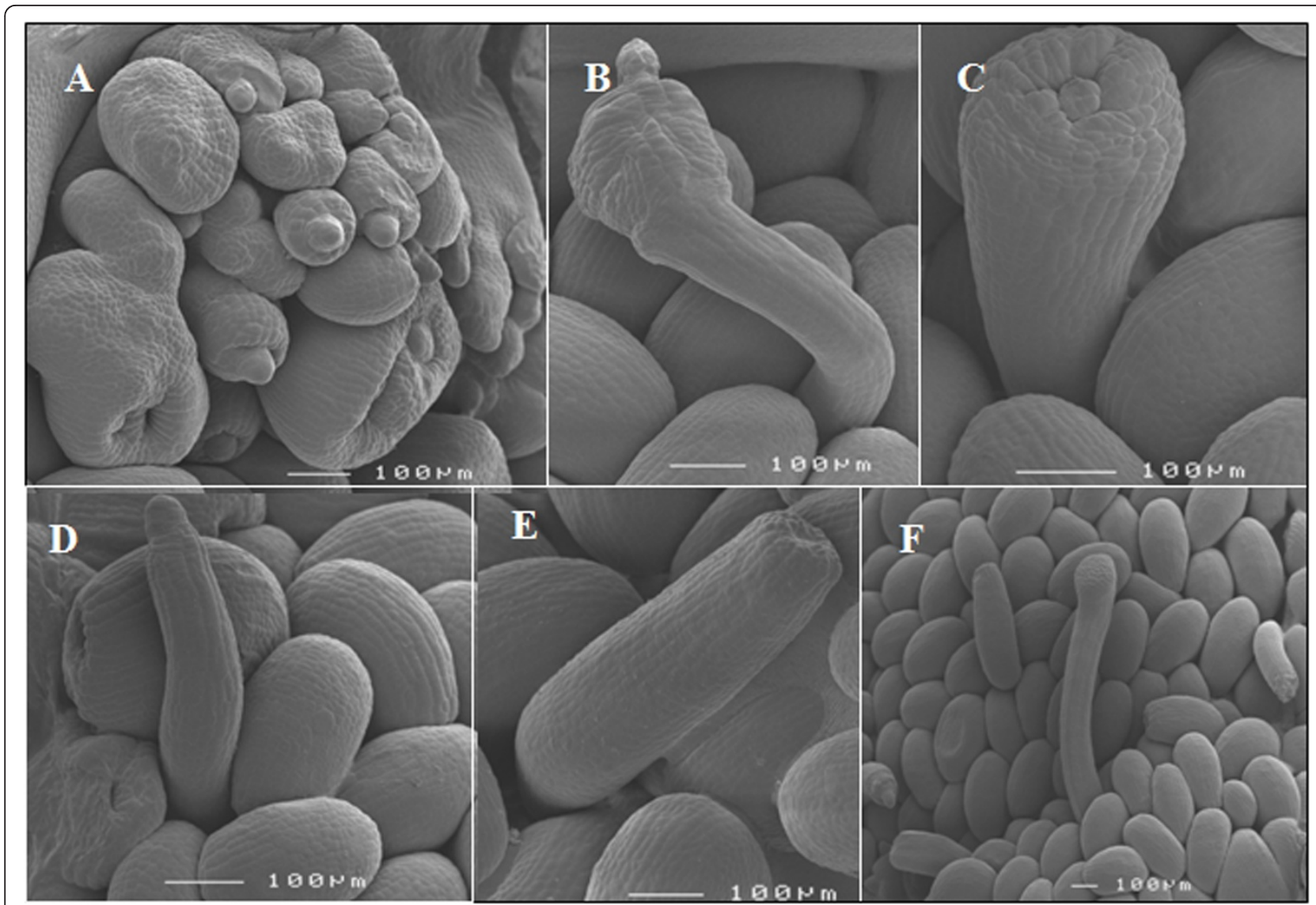

Figure 3 Cryo-scanning electron microscopy images showing abnormal ovule development in Capsicum annuum genotypes. A-F Abnormalities detected in the three genotypes were excessive integument growth (A), or carpelloid proliferation of integuments and or the incomplete coverage of the nucellus (B), integuments failing to cover the nucellus (C). In some, ovule structures the integuments partially recurved (D) or were absent (E). Some ovule primordia lacked chalaza and nucellus specification (F). Bar $=100 \mu$ m. Genotypes Orlando, Bruinsma Wonder and Line 3 grown at $20 / 18^{\circ} \mathrm{C} \mathrm{D/N}$ were used for observation.

$\mathrm{C}$ as a high temperature. The number of seeds was always lower in Line 3 compared to BW at low (0 versus $34 \pm 1.5)$, normal $(18 \pm 2.8$ versus $54 \pm 5.1)$ and high temperature $(44 \pm 2.8$ versus $101 \pm 5.5)$ (Figure 4B). Thus, in Line 3 the high number of abnormal ovules correlated with a precocious occurrence of carpelloid structures and lowered seed set, suggesting that the ovule semi-sterility might also be in part related to the parthenocarpic potential in Line 3.

In all three tested genotypes (OR, BW and Line 3), carpelloid structures were observed as internal green abnormal structures arising from the placenta. The carpelloid structures often had an extensive growth from the placenta (Figure 4C-F). They varied in size from small to large, and in appearance, as mildly (Figure 4D) to severely deformed (Figure 4E). Most of the time the carpelloid structures remained green even after ripening of the fruits and stayed firmly attached to the placenta. Only occasionally, red coloured carpelloid structures were observed in a ripe fruit. The size and weight of carpelloid structures increased with the age of the fruit and for some fruits the carpel margin boundaries were split as carpelloid structures continued to grow to the outside of the fruit (Figure 4F).

\section{Correlation between carpelloid structures and fruit size in phytohormone-induced parthenocarpy}

We used the genotype BW that has moderate parthenocarpic potential [16], to test and observe the relationship between carpelloid growth and seed set, and the effect of phytohormone application on carpelloid proliferation. To obtained seedless fruits, flowers were emasculated prior to anthesis and lanolin paste was applied at anthesis. Emasculated flowers treated with or without hormones (NAA, $\mathrm{GA}_{3}$ ), resulted in only seedless fruits. Emasculation alone resulted in low fruit set (25\%). Hormone application on emasculated flowers improved fruit set (30\% for NAA, 38\% for $\mathrm{GA}_{3}$ ) compared to fruit set obtained after natural pollination (28\%). However, the final fruit fresh yield (excluding knots) was higher in 


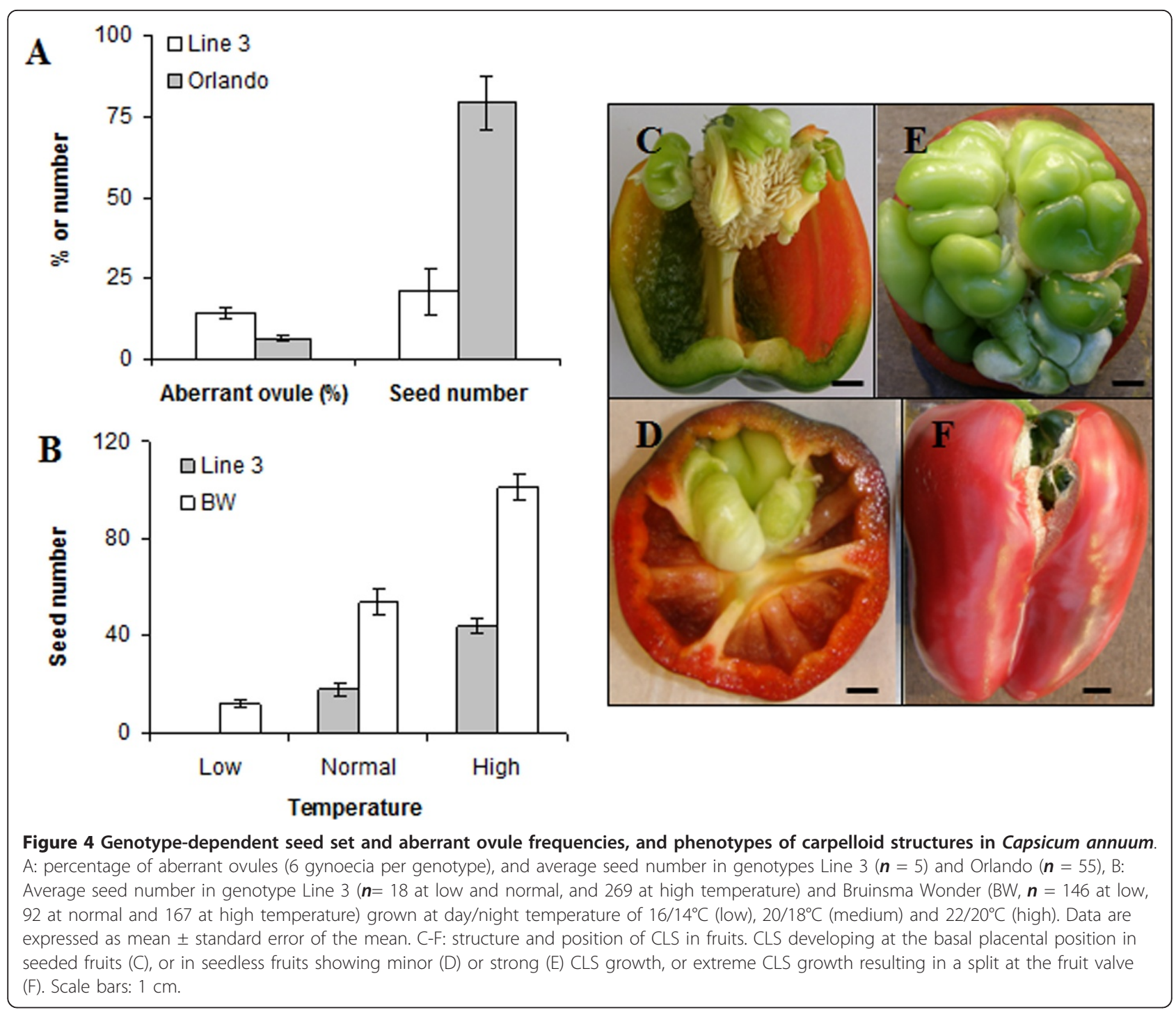

seeded fruits $\left(9.7 \mathrm{~kg} / \mathrm{m}^{2}\right)$ compared to seedless fruits (NAA; $6.9 \mathrm{~kg} / \mathrm{m}^{2}, \mathrm{GA}_{3} ; 6.2 \mathrm{~kg} / \mathrm{m}^{2}, \mathrm{Em} ; 4.3 \mathrm{~kg} / \mathrm{m}^{2}$ ).

In seeded fruits a positive correlation was observed between fruit fresh weight and seed number up to about 100 seeds (Figure 5A). For seedless fruits, only those fruits that reached at least $50 \%$ of the weight of seeded fruits were considered as parthenocarpic fruit and were used in the analysis. More than $90 \%$ of both seeded and seedless fruits showed carpelloid structures on their placenta. The average number of carpelloid structures did not differ between seeded and seedless fruits $(P=$ 0.382), but the average weight of carpelloid structures was significantly higher in parthenocarpic fruits $(P<$ 0.001 ) (Figure 5B). However, external application of hormones did not influence carpelloid proliferation in either mean number or mass compared to emasculation alone (number of carpelloid structures for $\mathrm{Em} 7.3 \pm 0.7$; $\mathrm{Em}+\mathrm{GA}_{3}, 8.3 \pm 0.4 ; \mathrm{Em}+\mathrm{NAA}, 7.2 \pm 0.6$; weight in $\mathrm{Em}$
$9.4 \pm 1.0 \mathrm{~g} ; \mathrm{Em}+\mathrm{GA}_{3} 7.9 \pm 0.6 \mathrm{~g} ; \mathrm{Em}+\mathrm{NAA}, 9.2 \pm 0.8$ g). Thereforeeven with various treatments a positive correlation between seedless fruit (\%) and carpelloid weight was observed (Figure 5B). Furthermore, it was observed that seedless fruit weight, excluding carpelloid structures, increased proportionally with the internal carpelloid mass (Figure $5 \mathrm{C}-\mathrm{E}$ ), suggesting a strong synergistic effect between the presence of carpelloid structures and seedless fruit growth.

\section{Inheritance of parthenocarpy and the relationship with CLS}

To study the genetic basis and inheritance of the parthenocarpic potential in C. annuum, the parthenocarpic genotype Line 3 was crossed with the non-parthenocarpic parents Lamuyo $\mathrm{B}, \mathrm{OR} \mathrm{F}_{2} \# 1$ (a male sterile plant selected from an $F_{2}$ population) and Parco. Since Line 3 is a small fruited genotype (Additional file 2; with an 


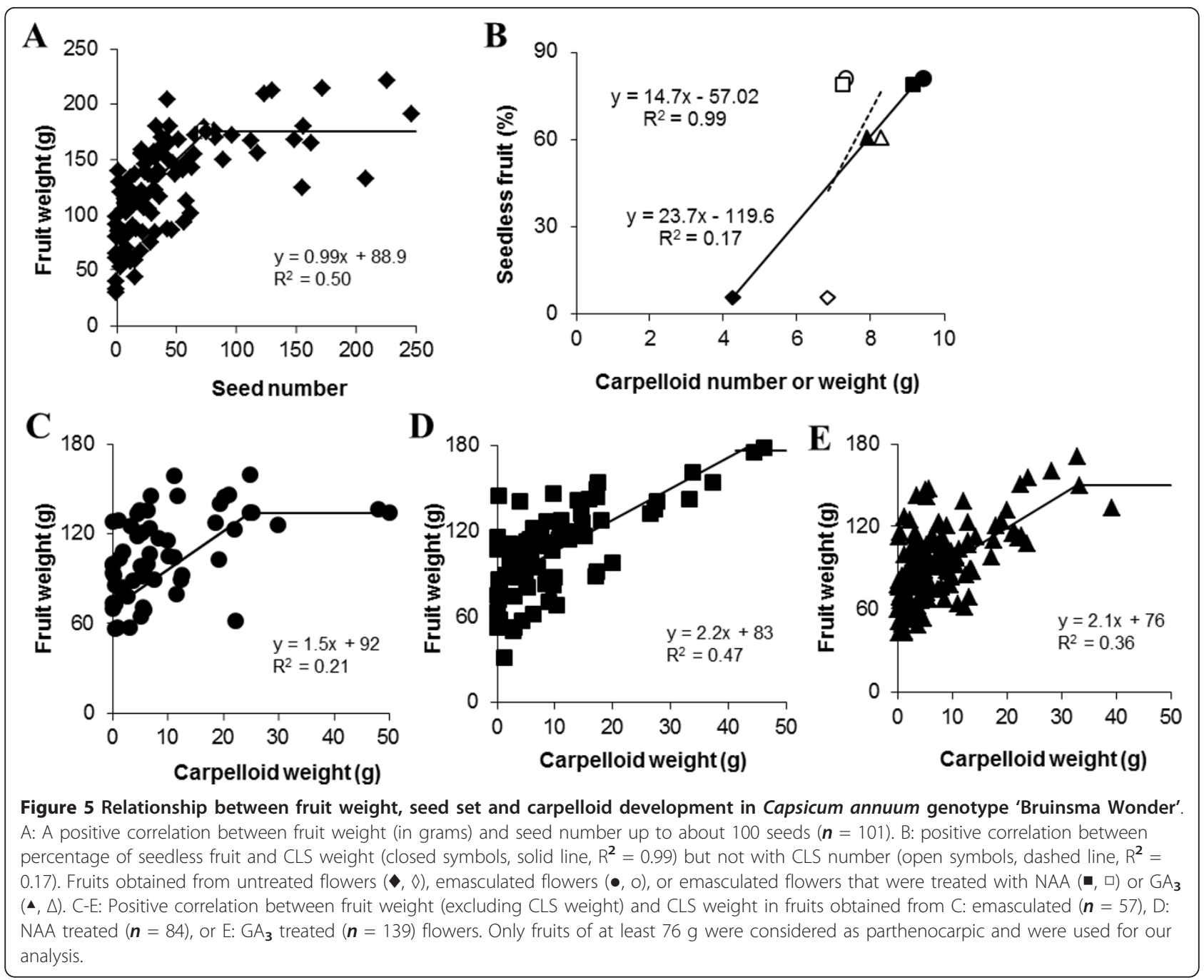

average fruit weight of $121 \mathrm{~g}$ ) and Lamuyo B is a large fruited genotype (average weight of $208 \mathrm{~g}$ for seeded fruit; [16], fruit size traits segregated independently upon crossing. This precluded fruit size as the sole criterion to distinguish fruit from knots as discussed earlier. Instead, we took the appearance of fruit as the criterion to distinguish true seedless fruit of small size (shiny appearance, additional file $2 \mathrm{C}$-E) from knots (dull appearance, additional file $2 \mathrm{D}-\mathrm{H}$ ). In the $\mathrm{F}_{2}$ analysis, a plant was considered parthenocarpic when emasculated flowers all produced seedless fruits showing a shiny appearance. In all three $F_{2}$ populations parthenocarpic plants were observed in 1:3 ratios. Furthermore when the $F_{1}$ of Line $3 \times$ Lamuyo $B$ was backcrossed with Line 3, parthenocarpy was observed in a 1:1 ratio. These data support the hypothesis that parthenocarpy present in Line 3 is controlled by a single recessive gene (Table 2). The same $F_{2}$ plants were evaluated for the occurrence of carpelloid structures. We used two different criteria to distinguish carpelloid from non-carpelloid plants; (i) a less stringent one where plants were scored as having the carpelloid trait if all the true seedless fruits contained at least one carpelloid structure and plants with no seedless fruits were excluded from the

\section{Table 2 Analysis of segregating population for} parthenocarpic fruit set

\begin{tabular}{|c|c|c|c|c|c|c|c|}
\hline \multirow[t]{2}{*}{ Crossing } & \multirow[t]{2}{*}{ Generation } & \multirow{2}{*}{$\begin{array}{l}\text { Expected } \\
\text { ratio }\end{array}$} & \multirow[t]{2}{*}{ Total } & \multicolumn{4}{|c|}{ Parthenocarpic } \\
\hline & & & & 0 & $E$ & $\mathrm{x}^{2}$ & $P$ \\
\hline \multirow{2}{*}{$\begin{array}{l}\text { Line } 3 \times \\
\text { Lamuyo B }\end{array}$} & $\mathrm{F} 2$ & $1: 3$ & 42 & 10 & 10.5 & 0.03 & 0.86 \\
\hline & $\mathrm{F} 1 \times$ Line 3 & $1: 1$ & 41 & 20 & 20.5 & 0.02 & 0.88 \\
\hline $\begin{array}{l}\text { Line } 3 \times \mathrm{OR} \\
\mathrm{F}_{2} \# 1\end{array}$ & $\mathrm{~F} 2$ & $1: 3$ & 62 & 17 & 15.5 & 0.19 & 0.66 \\
\hline Line $3 \times$ Parco & F2 & $1: 3$ & 24 & 5 & 6.0 & 0.22 & 0.64 \\
\hline
\end{tabular}

$F_{2}$ population analysis for parthenocarpy in crosses of Line $3 \times$ Lamuyo $B$, Line $3 \times \mathrm{OR} \mathrm{F}_{2} \# 1$ and Line $3 \times$ Parco, tested by chi-square distribution assuming monogenic recessive inheritance. (O: observed, E: expected, P: probability) 
analysis and (ii) a more stringent one by which plants were scored as having the carpelloid trait if more than $75 \%$ of all the true seedless fruits contained at least one carpelloid structure and plants with less than two seedless fruits were excluded from the analysis. However, taking either criterion into consideration, no mono- or digenic-models could explain with any level of significance the observed carpelloid/non-carpelloid segregation pattern.

Ninety-four percent of the fruits of Line 3 and $40 \%$ of $\mathrm{OR} \mathrm{F}_{2} \# 1$ fruits contained carpelloid structures. Both the average number $(P<0.001)$ and the weight $(P=0.011)$ of carpelloid structures per seedless fruit was higher in Line 3 than in $\mathrm{OR} \mathrm{F}_{2} \# 1$ at $21 / 19^{\circ} \mathrm{C} \mathrm{D} / \mathrm{N}$ temperature. This agrees with the results described above that the genotypes with a higher potential for parthenocarpy always produced more carpelloid structures.

\section{Parthenocarpic potential in C. annuum is not caused by a mutation in CaARF8}

Similar to tomato and Arabidopsis, a mutation in the $A R F 8$ gene might lead to the parthenocarpic phenotype in Line 3. Sequence analysis was performed for a contiguous section of $7508 \mathrm{bp}$ for CaARF8 (including $1816 \mathrm{bp}$ of the promoter region plus part of the 3'UTR) in Line $3, \mathrm{BW}$ and OR (Additional file 3). Differences in the sequence were not observed between any of the three genotypes (Addition file 3), indicating that the differences in parthenocarpy are not caused by mutations in the CaARF8 gene.

\section{Discussion}

Most C. annuum genotypes have parthenocarpic potential As an initial step in our attempt to characterize parthenocarpy in C. annuum, we tested several genotypes for their potential to set seedless fruits following emasculation. In line with our previous findings [16], most $C$. annuum genotypes developed seedless fruits following emasculation (Table 1), suggesting that some degree of intrinsic parthenocarpy is already present in these genotypes. Genetic variation for the strength of parthenocarpic fruit development was observed (Figure 1), which may occur due to genotypic differences in endogenous auxin and/or gibberellin content in the ovaries or placenta. Genotypes with high potential for parthenocarpy could contain higher levels of hormones compared to those with a lower potential [20]. Intriguingly, however, we also observed that the genotype with the highest parthenocarpic potential (i.e. Line 3) showed reduced female fertility and seed set, and developed significantly more aberrant ovules as compared to the genotype for which no seedless fruit development was observed (OR). Pollination at higher temperatures did not lead to complete seed set in Line 3 whereas it did in BW, supporting the hypothesis that reduced female fertility is associated with enhanced parthenocarpy in Line 3. This hypothesis is corroborated by our previous observation that the expression of parthenocarpy was most prominent in Line $3(100 \%)$ and Lamuyo B (70\%) at low night temperature, which leads to further reductions in male fertility (Additional file 1), while this was reduced in Line $3(73 \%)$ and not detectable in Lamuyo B (0\%) at normal night temperature [16]. Reduced fertility from aberrant ovules and aberrant anther development is an associated or perhaps even a causal developmental phenotype leading to parthenocarpy in the tomato pat mutant (pat allele) [21]. Precocious carpelloid growth was observed in Line 3 compared to OR, suggesting that Line 3 contains traits leading to precocious parthenocarpy and or carpelloid transformation well before fertilization. Likewise it has been reported that parthenocarpic fruit development is characterized by autonomous and precocious onset of ovary development in tomato and Arabidopsis [2,22].

\section{Number and mass of carpelloid structures is influenced by genotype}

Carpelloid development was observed in all C. аnnuиm genotypes tested, which is in agreement with Lippert [23] who reported that carpelloid structures are present in a wide range of Capsicum varieties, but are most commonly observed proliferating in accessions with the bell or blocky type of fruit which have an axial type placenta. Here we show that the resulting number and weight of carpelloid structures was genotype dependent (Figure 1A-H) and that carpelloid development was observed in genotypes possessing a high potential for parthenocarpy. This suggests both traits synergistically interact with one another, or that parthenocarpy promotes proliferation of aberrant ovule primordia. Interestingly, the severity of carpelloid structure is reported to be ecotype dependent also for the Arabidopsis bel1 mutant [11]. Though the identity of the ecotype enhancer is unknown, several other genetic loci have cooccurring carpelloid-parthenocarpy proliferation. These are the Arabidopsis knuckles mutant which is defective in the MAC12.2 gene and the tomato mutant $\operatorname{tm} 29$, where the down regulation of TM29 (SEPALLATA homolog) transcription factor results in similar synergistic development of carpelloid tissue proliferation and parthenocarpy $[24,25]$. This possibly points to a consistent regulatory link between both traits [25].

In most flowering plants, flowers consist of sepals (first whorl), petals (second whorl), stamens (third whorl), and pistils (fourth whorl) [26]. In the Arabidopsis fwf-1/arf8-4 mutant, the third whorl organs have an inhibitory effect on parthenocarpic silique development, [2]. In the male sterile pop1/cer6-1 background, the fwf- 
1/arf8-4 parthenocarpy mutation only induces strong silique growth when the stamens are removed. The requirement of emasculation is negated when the pop1/ cer6-1 - fwf-1/arf8-4 double mutant is combined with the ats-1/kan4-1 mutant, which has a lesion in ovule integument development [2]. This suggests that the inhibitory signal derived from the stamens, in the third whorl, acts through the ovule integument (fourth whorl) to retard parthenocarpic silique development in $f w f-1 /$ arf8-4 [2]. In C. annuum, we observed parthenocarpic fruit set was enhanced by carpelloid structures. Assuming that carpelloid structures are a form of homeotically converted aberrant ovules, their growth could be governed partially by third whorl identity regulators, but the functions regulating fruit set, either through an independent or a shared pathway, need to be further examined.

\section{Inheritance of parthenocarpy and relation between parthenocarpy and carpelloid structures}

The expression of parthenocarpy in the C. annuum genotype Line 3 is facultative, producing seeded and or seedless fruits depending on growth conditions but some semi-sterility is present. We studied the inheritance of parthenocarpy in Line 3 at normal temperatures by using emasculation, and found that the parthenocarpic potential in Line 3 is linked to a single recessive gene (Table 2). Recessive mutations inducing facultative parthenocarpy have been reported before in tomato, citrus and Arabidopsis [2,5,27]. Mutations in Arabidopsis $A R F 8$ can provide parthenocarpy, but it can also be obtained when defective forms of $A R F 8$ are expressed in Arabidopsis and tomato [4]. In the $C$. annuum cultivars tested the CaARF8 sequences were indifferent, excluding that the occurrence of parthenocarpy is caused by a mutation in the coding region of this gene.

In our $\mathrm{F}_{2}$ analysis no simple inheritance pattern was observed for carpelloid growth and no clear genetic relationship could be established between the presence of carpelloid structures and parthenocarpy. Perhaps a reason for this is that all parental genotypes used in the three crosses showed some degree of carpelloid transformation (92\% fruits with carpelloid structures in Line 3, $56 \%$ in Lamuyo B, $46 \%$ in OR [16]. The ubiquitous nature of carpelloid structures, but synergistic interaction with parthenocarpy, suggests a non-mendelian inheritance. In order to study the inheritance of this trait, a parental genotype completely devoid of carpelloid growth would be needed. Additionally the strong association between parthenocarpy and carpelloid structures indicates that breeding for high parthenocarpic potential in the absence of carpelloid development will be an important challenge for breeders to overcome.

\section{Abnormal ovule development and reduced seed set, enhanced carpelloid development and parthenocarpic fruit size}

C. annuиm has an axillar placenta where ovules develop in a gradient from top to bottom. The majority of the ovules are anatropous and unitegmic, as is characteristic for the Solanaceae family [28]. Deviations in normal ovule development were observed mainly at the top and base of the placenta (Figure 2), which might be due to abnormal integument growth. A similar pattern of deviations was reported in Arabidopsis and petunia where abnormal integument growth resulted in an abnormal ovule mainly at the top and the base of the placenta [29,30] and Cochran [31] showed that carpelloid structures histologically resemble carpel tissue. Stunted integuments in some Solanaceae may have a genetic basis since Angenent and co-workers [30] suggested that reduced resource availability may lead to aberrant ovule growth in petunia. The genotype Line 3 contained a high fraction of aberrant ovules and also contained high carpelloid growth compared to OR. Although our data can not exclude that carpelloid structures arise de novo directly from the placenta, it is likely that the majority result from homeotic ovule primordia conversions.

An inverse relation between the percentage of aberrant ovules and seed number was observed when comparing the genotypes Line 3 and OR (Figure 4A), suggesting semi-sterility is present in Line 3 . This might explain why pollination even at normal and high night temperature did not improve the seed set in Line 3 compared to BW (Figure 4B). Moreover it may be the reason why the parthenocarpic potential is higher in Line 3 as compared to other genotypes. The reduced fertility might allow a window of opportunity for increased expression of parthenocarpic potential.

In general, fruit weight was positively correlated with seed number and in the absence of seeds fruit weight proportionally increased with the carpelloid mass (Figure 5A-F). This suggests that carpelloid growth could substitute for growth signals that normally occur only after pollination and fertilization, mimicking the role of developing seeds. In the absence of fertilization, carpelloid structures can acquire available assimilates and grow prominently, but seeds could however compete better for the assimilates explaining the inverse relationship (Figure 4A)

\section{Conclusions}

Based on our findings we postulate a model indicating the role of fertility, aberrant ovules and carpelloid growth in parthenocarpic fruit set and development (Figure 6). Carpelloid development positively reinforces fruit growth, particularly in genotypes showing 


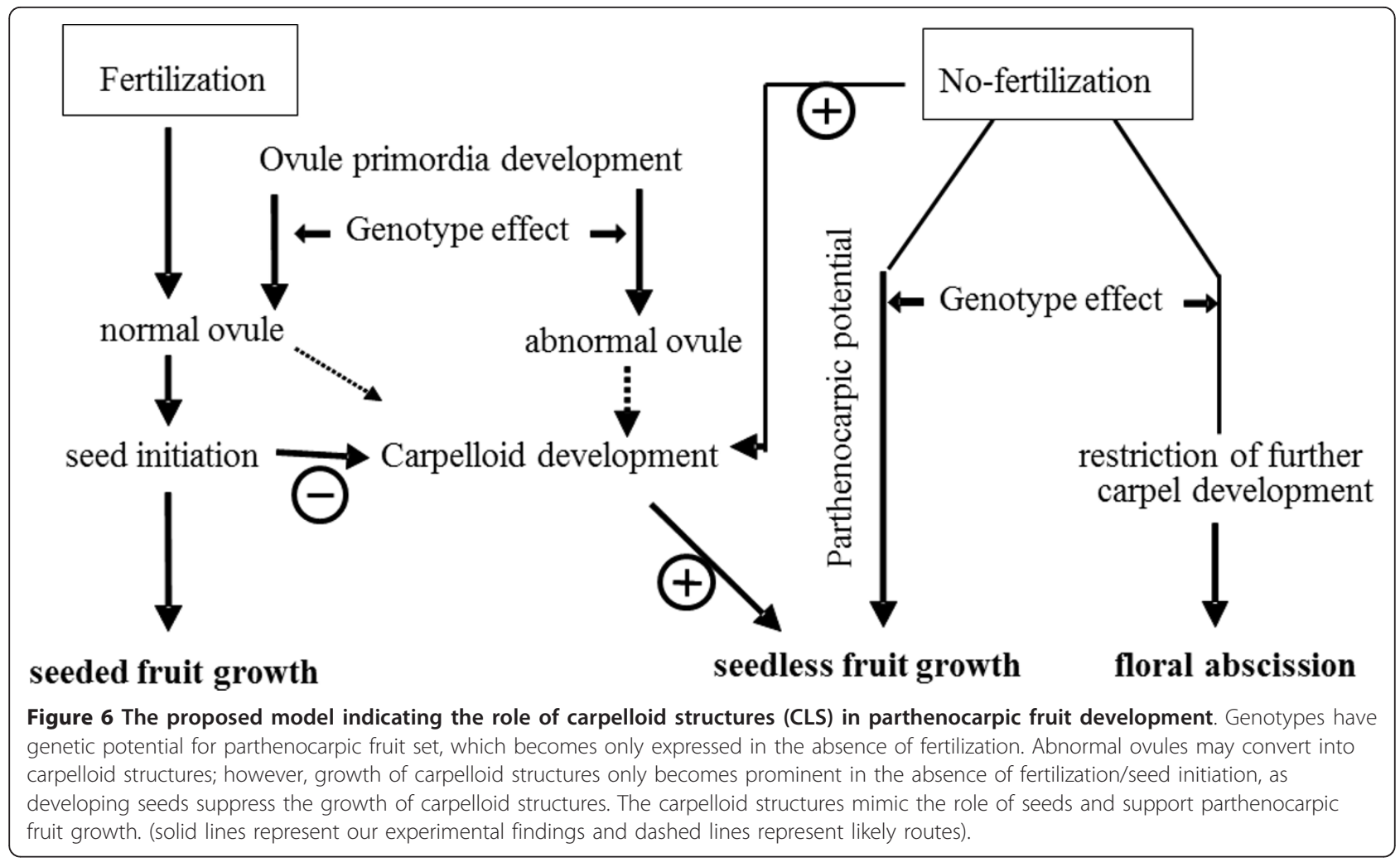

parthenocarpic potential. Abnormal ovules may convert into carpelloid structures, however, growth of carpelloid structures only becomes prominent in the absence of fertilization, indicating fertility as an important determinant of their development. In agreement with this model, genotype Line 3 showed reduced fertility and developed more carpelloid structures. Upon fertilization, normal seed development occurs, inducing fruit set but possibly suppressing carpelloid proliferation. Facultative parthenocarpy is widely present in C. annuum genotypes, and the absence of fertilization allows the parthenocarpic potential to be expressed, and at the same time induces carpelloid proliferation, possibly following the homeotic transformation of abnormal ovules.

\section{Methods}

\section{Greenhouse conditions}

The genotypes and greenhouse conditions used in different experiments are summarized in Additional file 4. In all the experiments, seeds were transferred on rockwool cubes with regular supply of nutrient solution [32]. Seedlings were transplanted on rockwool slabs at a density of 2.5 plants $\mathrm{m}^{-2}$ in a compartment of a multispan Venlo-type glasshouse or in an air conditioned glasshouse, Wageningen, The Netherlands. Supplemental lighting by high pressure sodium lamps (Philips, SON-T, $600 \mathrm{~W}$ ) for 16 hours (from 06.00 to 22.00) provided a minimum photon flux density of $125 \mu \mathrm{mol} \mathrm{m}{ }^{-2} \mathrm{~s}^{-1}$ at the crop level. The terminal flower was removed from all plants at anthesis to support vegetative growth.

\section{Occurrence of parthenocarpy among C. annuum genotypes}

C. annuum (Table, 1) genotypes were selected on the basis of their blocky appearance and seed number (Additional file 4: Exp 1). In total, 70-150 emasculations were performed in each genotype using 10 plants per genotype and fruit set was evaluated when fruits were ripe.

\section{Genotype effect on number and weight of carpelloid structures}

Five genotypes: Parco, California Wonder 100 (CW), Riesen v. Californien (RVC), Bruinsma Wonder (BW), and Line 3 were arranged in one row of 8 plants at two temperatures $\left(20 / 18^{\circ} \mathrm{C}, 16 / 14^{\circ} \mathrm{C} \mathrm{D} / \mathrm{N}\right.$ ) (Additional file 4: Exp 2). Two treatments (induced pollination or preventpollination) were completely randomized within the row. Induced pollination was done by vibrating the stem two times per week. Prevent-pollination was done by applying lanolin paste on the stigma of the flowers [33]. In genotypes Parco, RVC, CW and Line 3, flowers were given the treatments till three fruits per plant were obtained. In genotype BW, two flowers (one on main 
branch and one on a side branch) were treated at each of 20 nodes. Mature red fruit were harvested and their length, diameter and fruit fresh weights were recorded. Those seedless fruits that reached minimum of $50 \%$ of the weight of seeded fruit were considered as parthenocarpic and were used in our analysis while remaining were considered as knots. The number of seeds and number of carpelloid structures was counted in each fruit and each carpelloid structure was weighed.

\section{Ovule development in C. annuum}

Line 3 and BW were inbred lines with high and medium potential to set parthenocarpic fruits [16] while Orlando (OR) was a fourth-generation inbred line developed from Orlando-F1 (De Ruiter seeds) (Additional file 4: Exp 3). Flowers were collected at 3-4 days before balloon stage. Pericarp was removed and morphological analysis of ovule development was conducted in the laboratory by using a field-emission cryo-scanning electron microscopy (SEM) (Jeol 6300F), equipped with an Oxford CT 1500HF cyro-stage system [34].

\section{Correlation of abnormal ovule development with reduced seed set and enhanced development of carpelloid structures}

Two set of experiments were conducted (Additional file 4: Exp 4). In first experiment, genotypes Line 3 and OR were used to evaluate the occurrence of carpelloid structures. Flowers were tagged at 2 days before anthesis and allowed to pollinate naturally. Developing ovaries were harvested at 2 days of interval, dissected and evaluated for the presence of carpelloid structures by visual inspection. With the same set of genotypes, percentage of aberrant ovules and number of seeds was evaluated. Flowers $(n=6)$ were collected randomly at or around the anthesis stage. After removing the carpel, ovules were scraped smoothly in a water medium on a clean slide and the frequency of abnormal ovules was observed under optical microscope (Leitz Aristoplan). Seed set was counted when fruits reached the maturity (red) in both genotypes. In second experiment, genotypes Line 3 and BW were used. To evaluate the female fertility, plants were grown at day/night temperature of $14 / 16^{\circ} \mathrm{C}$ (low), $18.20^{\circ} \mathrm{C}$ (normal) and $22 / 24^{\circ} \mathrm{C}$ (high) and pollination was induced by vibrating the main stem two times per week. Number of seeds was counted when fruits reached the maturity (red) in both genotypes.

\section{Pollen viability and germination}

Pollen grains of BW were collected from normal temperature $\left(20 / 20^{\circ} \mathrm{C}\right.$ day/night $)$ and low night temperature (20/10 ${ }^{\circ} \mathrm{C}$ day/night) in morning time (9.00-10.00 PM) (Additional file 4: Exp 5). To test the pollen viability, hydrated pollens were dissolved in FDA solution [35] and scored under fluorescence microscope. Pollen which fluoresced brightly under fluorescence was scored as viable. For pollen germination, the hanging drop technique was employed following published procedures [36] with some modifications. A liquid medium containing $0.25 \mathrm{mM}$ MES (pH5.9), 15\% (w/v) PEG 4000, 2\% (w/v) sucrose, $700 \mathrm{ppm} \mathrm{Ca}\left(\mathrm{NO}_{3}\right)_{2}, 100 \mathrm{ppm} \mathrm{H}_{3} \mathrm{BO}_{3}, 200 \mathrm{ppm}$ $\mathrm{MgSO}_{4}, 100 \mathrm{pm} \mathrm{KNO}_{3}$ ) was used. Germination was considered only when germinating tube was larger or equal to the size of the pollen. Viability and germination percentages were determined, using 10-12 replicates of about 20-40 selected grains.

Relation between parthenocarpy and carpelloid structures Genotype BW with moderate potential for parthenocarpy was used in the experiment (Additional file 4: Exp 6). To obtain seeded fruits, flowers were tagged at anthesis and allowed to pollinate naturally. To obtained seedless fruit, flowers were emasculated two days before the expected date of anthesis and stigmas were cover with the lanolin paste or lanolin paste containing $0.05 \%$ 1-Naphthaleneacetic acid (NAA) or Gibberellic acid $\left(\mathrm{GA}_{3}\right)$ [33]. Fifteen plants per treatment were used. On each plant, two flowers (one on main branch and one on a side branch) were treated at each of 20 nodes. All the fruits were harvested at mature red stage and their length, diameter and fruit fresh weights were recorded. Criteria to define parthenocarpic fruit and knot were the same as mentioned earlier (Exp.2). The number of seeds and number of carpelloids structures was counted in each fruit and each carpelloids structure was weighed.

\section{Inheritance of parthenocarpy and its relation with carpelloid structures}

In order to understand the genetics of parthenocarpy and a possible association with carpelloids structures, genetics of both traits were evaluated in cross progenies of Line 3 (Additional file 4: Exp 7). Line 3 was used as a parthenocarpic parent (Pp) and Lamuyo B, ORF2\#1, and Parco as non-parthenocarpic parents $(\mathrm{Pn}) . \mathrm{F}_{2}$ progenies were obtained for all three crosses, and also a backcross with Line 3 in the cross with Lamuyo B. The flowers (15-20) were emasculated prior to anthesis and tagged. All the fruits were harvested at the mature red stage. Length, diameter and fruit fresh weights were recorded for individual fruits. In each fruit, carpelloids structures were counted and mass were weighed. All three crossing population were evaluated and mono- or digenic-models were tested to understand the genetics behind parthenocarpy and carpelloids structures.

\section{Sequence analysis of CaARF8}

Young leaf material from Line 3, BW and OR (Additional file 4: Exp 8) was collected for DNA extraction. 
Primers for PCR amplification were designed against pepper, tomato and potato ARF8 EST sequences available from the Sol Genomics Network (SGN), http://solgenomics.net/ (Additional file 5). SEFA PCR was used to amplify non-transcribed regions. PCR products were cleaned with the Invitek MSB ${ }^{\circledR}$ Spin PCRapace. $120 \mathrm{ng}$ of PCR product per reaction was sent with the appropriate sequencing primer (12 pmol) to ServiceXS, Leiden, The Netherlands. Resulting chromatograms were manually trimmed and checked for calling errors. Contigs were built by using Contig Express of the Invitrogen Vector NTI suite Version 10.4.

\section{Statistical analysis}

Experiments and their statistical treatment are listed in additional file 4. For experiment 3 and 4, one way analysis of variance (ANOVA) was used, and treatment effects were tested at 5\% probability level using F-test. For experiment 5 , the effect of each treatment on each genotype at each temperature was tested separately by using a one way analysis of variance (ANOVA). Mean separation was done by student's t-test. Data processing and statistical tests were carried out with SPSS 15.0. The inheritance of parthenocarpy was tested by using chi square distribution with 1 degree of freedom at the 0.05 level of significance to test the null hypothesis that parthenocarpy was controlled by a single recessive gene. Carpelloid inheritance was tested using a chi square distribution, with different mono- or digenic models.

\section{Additional material}

Additional file 1: Pollen viability and germination in Capsicum annuum genotypes. Pollen viability and germination for genotypes Bruinsma Wonder and Lamuyo B grown at normal $\left(20 / 20^{\circ} \mathrm{C}\right)$ and low $\left(20 / 10^{\circ} \mathrm{C}\right)$ day/night temperature. Different letters indicate significant differences between genotype-temperature combinations according to the LSD-test ( $\boldsymbol{P}=0.05, \boldsymbol{n}=5$-7 replicates).

Additional file 2: Fruit characteristics used in the segregation analysis. A-B: Fruit shape and size of genotype Line 3, C-E: seedless fruit of shiny appearance and pointy bottom (C), and large depression on bottom (D), and small size (E); F- H: small size knots of partial dull appearance $(F)$, big $(G)$, and small $(H)$ knots of fully dull appearance; I: seeded fruit. Plants were grown at $21 / 19^{\circ} \mathrm{C} / \mathrm{N}$ temperature. Scale bars: $1 \mathrm{~cm}(\mathrm{~A}-\mathrm{l})$.

Additional file 3: Capsicum annuum ARF8 genomic sequence in genotypes Line 3, Orlando and Bruinsma Wonder. Exons are marked green, dark grey or light gray, depending on their correspondence to our CDNA clone, the Arabidopsis coding sequence or a Solgene EST, respectively, the translation start is marked yellow the miRNA167 binding site is marked blue.

Additional file 4: Summary of experimental setup (genotypes and greenhouse conditions) used in different experiments (Excel spreadsheet). The set of genotypes, their parthenocarpic fruit set potential, their origin, temperature set point and realized temperatures, cultivation method (one or two branch pattern system), and start month and end of the experiments.
Additional file 5: Primer sequences (Excel spreadsheet). Primer sequences used to amplify Capsicum annuum CaARF8 gene sequences.

\section{Acknowledgements}

We thank Hans Dassen, Ceclia Kgomotso Rabosielo and Maarten Peters for help with the greenhouse experiments and Werner Helvensteyn for sequencing. This work was supported by STW grant LB06822 to R.O., E.H. and A.V-S.

\section{Author details}

${ }^{1}$ Horticultural Supply Chains, Plant Sciences Group, Wageningen University, P. O. Box 630, 6700 AP Wageningen, The Netherlands. ${ }^{2}$ Molecular and Developmental Genetics, Institute of Biology, Leiden University, Sylvius Laboratory, Sylviusweg 72, 2333 BE Leiden, The Netherlands. ${ }^{3}$ Plant Research International, Plant Sciences Group, Wageningen University and Research Center, P.O. Box 16, 6700 AA Wageningen, The Netherlands. ${ }^{4}$ Department of Horticulture, Yangzhou University, Yangzhou, Jiangsu, PR China. ${ }^{5}$ Norwegian Forest and Landscape Institute, Høgskoleveien 8, 1431 Ås, Norway.

\section{Authors' contributions}

AT performed the experiments, interpretated the data and drafted the manuscript with guidance from EH, RO, REV and AVS. AVS and MEJH cloned and sequenced the CAARF8 gene. AT, EH, RO and AVS revised the manuscript. LBX performed the selection of Line 3 and provided seeds for this work. All authors read and approved the final manuscript.

Received: 24 June 2011 Accepted: 21 October 2011

Published: 21 October 2011

\section{References}

1. Fuentes S, Vivian-Smith A: Fertilization and fruit initiation. In Fruit development and seed dispersal. Volume 38.. 1 edition. Edited by: L Ostergaard. Norwich: UK; Wiley-Blackwell; 2009:107-171.

2. Vivian-Smith $A$, Luo $M$, Chaudhury A, Koltunow A: Fruit development is actively restricted in the absence of fertilization in Arabidopsis. Development 2001, 128:2321-2331.

3. Goetz M, Vivian-Smith A, Johnson SD, Koltunow AM: AUXIN RESPONSE FACTOR 8 is a negative regulator of fruit initiation in Arabidopsis. Plant Cell 2006, 18:1873-1886.

4. Goetz M, Hooper LC, Johnson SD, Rodrigues JCM, Vivian-Smith A, Koltunow AM: Expression of aberrant forms of AUXIN RESPONSE FACTOR 8 stimulates parthenocarpy in Arabidopsis and tomato. Plant Physiol 2007, 145:351-366.

5. Gorguet B, Eggink PM, Ocana J, Tiwari A, Schipper D, Finkers R, Visser RGF, van Heusden AW: Mapping and characterization of novel parthenocarpy QTLs in tomato. Theor Appl Genet 2008, 116:755-767.

6. Berger F, Hamamura Y, Ingouff M, Higashiyama T: Double fertilizationcaught in the act. Trends Plant Sci 2008, 13:437-443.

7. Baker SC, Robinson-Beers K, Villanueva JM, Gaiser JC, Gasser CS: Interactions among genes regulating ovule development in Arabidopsis thaliana. Genetics 1997, 145:1109-1124.

8. Lang JD, Ray S, Ray A: SIN1, a mutation affecting female fertility in Arabidopsis, interacts with MOD1, its recessive modifier. Genetics 1994, 137:1101-1110.

9. Leon-Kloosterziel KM, Keijzer CJ, Koornneef M: A seed shape mutant of Arabidopsis that is affected in integument development. Plant Cell 1994, 6:385-392

10. Elliott RC, Betzner AS, Huttner E, Oakes MP, Tucker WQJ, Gerentes D, Perez P, Smyth DR: AINTEGUMENTA, an APETALA2-like gene of Arabidopsis with pleiotropic roles in ovule development and floral organ growth. Plant Cell 1996, 8:155-168.

11. Modrusan Z, Reiser L, Feldmann KA, Fischer RL, Haughn GW: Homeotic transformation of ovules into carpel-like structures in Arabidopsis. Plant Cell 1994, 6:333-349.

12. Ray A, Robinson-Beers K, Ray S, Baker SC, Lang JD, Preuss D, Milligan SB, Gasser CS: Arabidopsis floral homeotic gene BELL (BEL1) controls ovule development through negative regulation of AGAMOUS gene (AG). PNAS USA 1994, 91:5761-5765. 
13. Pinyopich A, Ditta GS, Savidge B, Liljegren SJ, Baumann E, Wisman E, Yanofsky MF: Assessing the redundancy of MADS-box genes during carpel and ovule development. Nature 2003, 424:85-88.

14. Vivian-Smith A: The molecular basis for the initiation of fruit development and parthenocarpy. PhD thesis University of Adelaide Adelaide, Australia; 2001.

15. Heuvelink E, Körner O: Parthenocarpic fruit growth reduces yield fluctuation and blossom-end rot in sweet pepper. Ann Bot 2001, 88:69-74.

16. Tiwari A, Dassen H, Heuvelink E: Selection of sweet pepper (Capsicum annuum L.) genotypes for parthenocarpic fruit growth. Acta Hort 2007, 761:135-140.

17. Gaiser JC, Robinson-Beers K, Gasser CS: The Arabidopsis SUPERMAN gene mediates asymmetric growth of the outer integument of ovules. Plant cell 1995, 7:333-345.

18. Pressman E, Moshkovitch H, Rosenfeld K, Shaked R, Gamliel B, Aloni B: Influence of low night temperatures on sweet pepper flower quality and the effect of repeated pollinations, with viable pollen, on fruit setting. $J$ Hortic Sci Biotech 1998, 73:131-136.

19. Rylski I, Halevy AH: Optimal environment for set and development of sweet pepper fruit. Acta Hort 1972, 42:55-62.

20. Fos M, Proano K, Alabadi D, Nuez F, Carbonell J, Garcia-Martinez JL: Polyamine metabolism is altered in un-pollinated parthenocarpic pat-2 tomato ovaries. Plant Physiol 2003, 131:359-366.

21. Mazzucato A, Taddei AR, Soressi GP: The parthenocarpic fruit (pat) mutant of tomato (Lycopersicon esculentum Mill.) sets seedless fruits and has aberrant anther and ovule development. Development 1998, 125:107-114.

22. Mapelli S, Badino M, Soressi GP: Effect of $\mathrm{GA}_{3}$ on flowering and fruit set in a mutant of tomato. Hort Sci 1979, 14:736-737.

23. Lippert LF, Smith PG, Bergh BO: Cytogenetics of vegetable crops: garden pepper Capsicum Sp. Botan Rev 1966, 32:24-55.

24. Ampomah-Dwamena C, Morris BA, Sutherland P, Veit B, Yao JL: Downregulation of TM29, a tomato SEPALLATA homolog, causes parthenocarpic fruit development and floral reversion. Plant Physiol 2002, 130:605-617.

25. Payne $\mathrm{T}$, Johnson SD, Koltunow AM: KNUCKLES (KNU) encodes a $\mathrm{C}_{2} \mathrm{H}_{2}$ zinc-finger protein that regulates development of basal pattern elements of the Arabidopsis gynoecium. Development 2004, 131:3737-3749.

26. Immink RGH, Kaufmann $K$, Angenent $G C$ : The 'ABC' of MADS domain protein behaviour and interactions. Semin Cell Dev Biol 2010, 21:87-93.

27. Yamamoto $\mathrm{M}$, Matsumoto $\mathrm{R}$, Yamada $\mathrm{Y}$ : Relationship between sterility and seedlessness in citrus. J Jpn Soc Hortic Sci 1995, 64:23-29.

28. McAbee JM, Kuzoff RK, Gasser CS: Mechanisms of derived unitegmy among Impatiens species. Plant Cell 2005, 17:1674-1684.

29. Palser BF, Rouse JL, Williams EG: Coordinated timetables for megagametophyte development and pollen-tube growth in Rhododendron nuttallii from anthesis to early post-fertilization. Am J Bot 1989, 76:1167-1202.

30. Angenent GC, Franken J, Busscher M, van Dijken A, van Went JL, Dons HJM, van Tunen AJ: A novel class of MADS-box genes is involved in ovule development in petunia. Plant Cell 1995, 7:1569-1582.

31. Cochran HL: Abnormalities in the flower and fruit of Capsicum frutescens. J Agr Res 1934, 48:737-749.

32. Voogt W, Bloemhard C: Voedingsoplossingen voor de teelt van paprika in steenwol en bij hergebruik van drainwater. Voedingsoplossingen in de glastuinbouw 13. 5 edition. Research Station for Floriculture and Glasshouse Vegetables, Naaldwijk, The Netherlands; 1983.

33. Wien $\mathrm{HC}$, Zhang Y: Prevention of flower abscission in bell pepper. J Am Soc Hortic Sci 1991, 116:516-519.

34. Nijsse J, Walther P, Hoekstra FA: Cold-induced imbibition damage of lettuce embryos: A study using cryo-scanning electron microscopy. Seed Sci Res 2004, 14:117-126.

35. Heslop-Harrison J, Heslop-Harrison Y: Evalution of pollen viability by enzymatically induced fluorescence. Intra cellular hydrolysis of fluorescein diacetatae. Stain Tech 1970, 45:115-120.

36. Deng Z, Harbaugh B: Technique for in vitro pollen germination and short term pollen storage in Caladium. HortSci 2004, 39:365-367.

doi:10.1186/1471-2229-11-143

Cite this article as: Tiwari et al:: Parthenocarpic potential in Capsicum annuum $\mathrm{L}$. is enhanced by carpelloid structures and controlled by a single recessive gene. BMC Plant Biology 2011 11:143.

\section{Submit your next manuscript to BioMed Central and take full advantage of:}

- Convenient online submission

- Thorough peer review

- No space constraints or color figure charges

- Immediate publication on acceptance

- Inclusion in PubMed, CAS, Scopus and Google Scholar

- Research which is freely available for redistribution

Submit your manuscript at www.biomedcentral.com/submit
Biomed Central 